\title{
Why bioethicists have nothing useful to say about health care rationing
}

\author{
David Seedhouse University of Auckland
}

\begin{abstract}
Bioethicists are increasingly commenting on health care resource allocation, and sometimes suggest ways to solve various rationing dilemmas ethically. I argue that both because of the assumptions bioethicists make about social reality, and because of the methods of argument they use, they cannot possibly make a useful contribution to the debate. Bioethicists who want to make a practical difference should either approach health care resource allocation as if the matter hinged upon tribal competition (which is essentially what it does), or they should do political philosophy in the traditional sense, and examine the health system from the outside.
\end{abstract}

Although it is commonly supposed that bioethics can make a useful contribution to the debate about the rationing of health services (1-7) I argue that it cannot possibly do so. The problem is that bioethics is an approach which attempts to use rational methods, whereas the context in which health services rationing takes place is either nonrational or irrational.

\section{Rationality}

For the purposes of this paper:

a) I take 'rational activity' to mean 'activity consistently directed towards defined goals';

b) I take 'non-rational activity' to mean 'random activity' - or activity which has no detectable overall pattern, and

c) I take 'irrational activity' to mean 'activity consistently directed towards goals which are known to be conflicting'.

It is neither possible nor appropriate to present a technical paper on the nature of rationality in this journal (the topic is enormously complex) (8). But it is realistic (and important) to raise a question about

\section{Key words}

Bioethics; rationality; non-rational; irrationality; resource allocation; rationing. the role of bioethics in health care rationing. And in order to do this it is instructive to consider, briefly, $\overrightarrow{\text { or }}$ how far the techniques of bioethics might be usefuli in another context where rationing is often necessary ${ }_{\infty}^{\infty}$ - the context of the ordinary family. Below I describe음 one such family.

\section{The family}

This family is large - far larger than can be described in a short paper. However, for present purposes it is $\stackrel{B}{e}$ enough to study three of its component units. One gf these is made up of a mother and father, and therro four young children. They live in Auckland, Neqvis Zealand, both parents are unemployed, and the family is just about managing to keep going.

The second family unit is a single man (the $\stackrel{\mathbb{Q}}{\mathbb{Q}}$ brother of the mother in the first family unit). He is $\overrightarrow{\vec{\circ}}$ happy, well paid, and developing a flourishing 3 business (he lives in Wellington, New Zealand). $\mathrm{He}$ has no interest in the other members of the larger: family, and has long since ceased to attend any family gatherings.

The third family unit consists of around twentyo members - young and old - who all live in the same. area of Dunedin, New Zealand. This unit has been wealthy for many years (the family have been brewers for nearly a century), and their fortune is음 still increasing.

The first family unit has complained to the 'ethical ombudsman' that the family's resources are N unethically distributed. Could the ombudsman please propose an arrangement whereby resources are ethically rationed across the three units? Myc question is: what help can the bioethicist - in her role? as ethical ombudsman - offer in this situation?

It strikes me that a conventional bioethical response would be along these general lines. $A^{+}$ typical bioethicist would very likely take these four steps, and would:

i) isolate the specific problem from other family $\mathbb{\mathbb { Q }}$ matters judged to be not directly relevant - it is hard? to see what else the bioethicist can do if the problem is to be kept to a manageable size; 
ii) identify certain items of basic information, as well as key theoretical considerations - perhaps identify resources available, needs (maybe ranked in order of severity or degree of benefit), potential outcomes and so on;

iii) apply certain principles, or criteria, of fairness to the existing state of affairs, and also to alternative possible arrangements for the distribution of the family's resources, and

iv) suggest an ethical arrangement to the family as indicated by her ethical analysis (9).

Of course, it is never possible to predict absolutely the outcome of such analyses since different bioethicists favour different principles, and tend to weigh up the pros and cons of situations idiosyncratically: an egalitarian ethicist might suggest that the wealthiest family unit should simply donate money to the poorest one; the ethicist who favours meritocracy might propose that things are pretty much OK already (and that the Aucklanders had better pull their socks up); whilst the advocate of autonomy might suggest a (voluntary?) re-distribution, but only on condition that the money given to the poorest family unit be spent in ways aimed at the production of their long-term autonomy. As I say, the final result of such deliberations is always unpredictable. What is predictable, however, is that any ethical advice offered as a result of the four steps will miss the point: it will be detached from the reality of the family situation.

This should be obvious to anyone who has ever tried to effect rational change within a family. This sort of thing does not work since it does not take account of the history of the family (and their previous disputes), prevailing favouritisms and prejudices, the distribution of power, strength of feeling (the Dunedinite family unit, for instance, are firmly of the opinion that the Aucklanders are irresponsible hedonists), nor does this approach take irrationality into account (some members of some families will insist that black is white and will never be persuaded otherwise). And precisely the same reservation must apply to the endeavours of bioethicists who suggest ways of health care rationing solely through rational means.

\section{Examples from health care}

Before I set out my philosophical concerns directly I think it important to offer just a few examples from the life of the New Zealand medical family, so as to show a little of the real context in which some are presently seeking rational solutions in this country.

Private insurance is a boom industry in New Zealand, and public health services are being run down: under the one system you can get whatever medical service you can pay for (rationing by finance), on the other, if you cannot pay, you just get whatever service is available (or is offered to you by the system's guardians).

But what is and isn't available to you (under both systems) is hardly a result of rational planning. What is available is, in some combination, a product of commercial investment, political pressure, copying of health authorities in other parts of New Zealand and overseas, individual preference, power struggles between different disciplines, collective bias and so on. In other words, what is available is governed by the very messy real-world cultural and historical context, and not by planning according to logic and principle.

During the ten years in which I have worked as a philosopher in various medical schools I have seen many examples of quite blatant collective non-rationality and irrationality both in New Zealand and in the UK. And I have had just as many personal frustrations when trying to talk sensibly, and to offer thoughtful advice, about these non-rationalities and irrationalities. (The problem, it should be noted at this point, is not that individuals are irrational. Not at all. We are almost all [most of the time] highly rational and clear-thinking in the pursuit of our own ends within the system - the problem is that these ends, when taken together, are not compatible - and so it becomes impossible to identify a coherent rational end for the system as a whole.)

Briefly, here are just two 'medical family' situations I have come across in the last few months. Both illustrate the rationality problem. The first involved a severely physically (and most probably mentally) damaged neonate who had had - in a life of less than three months - several surgical operations. She was unable to breathe for herself and the question was: should ventilation be discontinued? Not an unusual case sadly, and I do not wish to discuss the ethics of it. Rather I want to draw attention to its non-rational and irrational features. For instance, once the treatment of neonates starts it becomes very difficult to stop it, and decisions to start or not to start tend to be based much more on hunches and feelings than hard evidence. I also want to draw attention to the fact that this baby's continued treatment (and I suspect extended misery) was not worked out. It just happened to be permitted because the consultant who happened to be in charge when the baby arrived at the neonatal unit believes in the sanctity of life, and the convention is that the admitting consultant retains overall charge of the case. Had a different consultant been on duty when the baby arrived it is likely that there would have been a different outcome (and an earlier death for the baby).

The issue in question in my second example was: should there be a look-back programme in New Zealand to trace recipients of blood donated by people who are now known to have been infected with the virus Hepatitis C? On the face of it this is a rational question - surely it must be possible to set up key criteria and apply ethical principles (rights 
maybe, utility perhaps) to sort out what to do? Of course, one may try, but because the world is the way it is, by using standard bioethics methods one will never get to the bottom of the matter, and it will be impossible to decide rationally between rival sets of criteria and principles.

In New Zealand in 1992 there was a political scandal which eventually led to the resignation of a government minister (an event virtually unheard of in this very conservative nation). The Australians had initiated screening of blood and blood products for Hepatitis C in 1989 (and were the first country in the world to do so) and by August 1990 there had been two recommendations from official New Zealand bodies that it be introduced here too. These suggestions were, it seems, disregarded by the New Zealand Ministry of Health. When the news media got hold of the story (it involved a number of young children so it was naturally considered fair game) there was quite a storm - lives are being lost for the sake of $\$ 10$ testing kits, and so on.

The news media made quite sure that the issue was not discussed in a rational climate, but in truth nothing about the situation had to do with collective rationality. Those people lobbying for the introduction of the screening test mostly had some sort of investment in it - either it was in their area of expertise, and naturally they were interested in providing the best service in their area (and - again naturally not so interested in the wider system), or they were personally worried about litigation, or they saw it as an opportunity to insist that the government provide better computing facilities (necessary for efficient look-back), or they had been offered free computing services by the manufacturers of Interferon (a drug with significant side-effects and questionable efficacy, but which might be of some help in 10-30 per cent of cases). Add to this the fact that prognosis, prevention, management and treatment of Hepatitis $C$ are highly uncertain (indeed many of those who test $\mathrm{HCV}+$ may remain asymptomatic for life), and it is hard to see how any sensible analysis is possible. In which case it must be asked: what is the role of the 'rational bioethicist' here? How can he or she say anything useful about the rationing of medical resources against such a background?

To suggest a rational change to a non-rational or irrational system cannot possibly produce the rationally predicted result - just as the introduction of a sweeper system (from soccer) would not produce a hoped-for improvement in the performance of an ailing rugby team. If, for instance, it were to be suggested that the QALY be implemented rigorously in a particular part of a health system (and it is quite unrealistic to suggest that it be used across the entire system since to do so would cause an unimaginable upheaval in conventional practice) the rest of the system would still operate according to its own rules. We would have a rigorous analysis in one place showing a list of benefits and costs. But this list would either be qựte useless (it would not be comparable with ot ther parts of the system which had not done fofie QALY analysis), or it would be absorbed by the larger system, and the results interpreted (eith̆er favourably or unfavourably) according to the interests of the most powerful parts of that system, as usual.

\section{Some conclusions}

I draw the following conclusions. They are not $\overrightarrow{T h e}$ sort of concerns that would normally be expected from a philosopher - they would, I think, be men more likely from a social scientist. However, this is how I have come to see the present state of bioethifs, and I think it is something that bioethicists mutst seriously work through before they engage with fhe health care rationing problem.

Currently bioethics studies the activities of those who practise medicine or subjects allied with medicine. It is critical of some (but by no means all) of these activities, and by applying mainly stock theories and principles, suggests ways of resolving some dilemmas (those dilemmas which seem to be most self-contained or independent of wider factops: whether to tell the truth to terminally ill perople, whether euthanasia is morally acceptable, amdcoso on). However, bioethics is rarely if ever critical ô context in which these activities are carried oft. Bioethics takes as given the prevailing situation which generates the activities it scrutinises. Jus the ethical ombudsman in my earlier example woyld not challenge the notion of 'family', with very exceptions bioethics:

1) does not challenge the dominance of medicine in health care;

2) does not challenge the deliberations and strategies of politicians, which partly contribute the climate of rationing;

3) does not compare the advantages and disadvantages of medical systems with other systems fin society;

4) sees the problem of health inequality largely a matter of access to those services which focus on the cure of disease or the amelioration of its symptoms; 5) does not question whether technology åd pharmacology ought to be society's major weapon against disease, and

6) (worst of all in a discipline which claims philosophical roots) does not engage in sustaiñed philosophical analysis of the meaning of key words such as health, well-being, medicine and diseasฐthat is, bioethics does not properly examine cenfral matters of health care purpose (10). Such analysis should be the foundation and starting point for all bioethics. It is certainly not possible to engerge seriously with health service resource allocation issues without this grounding. 
There are several reasons why it makes sense for bioethics to accept the background context uncritically: most bioethicists seek to be helpful; there continues to be a need expressed by practitioners for guidance in difficult situations; and in order to be accepted by the medical establishment bioethics really has no choice but to accept in turn most of the premises which underpin the medical system. As a result bioethicists are seen - and by and large are very content to be seen - as assistants in the broader scheme of things.

\section{Indigestible truths}

It is necessary to try to absorb two facts:

1. bioethics accepts uncritically the context which generates the problems it tries to deal with.

2 . bioethicists use reason and logic to solve bioethical dilemmas generated by the system.

These two facts would be digestible if the context and the bioethics method were compatible. But, as I have demonstrated, the context and the method are not compatible.

Instead, one way of thinking (from one culture if you like) is being applied to another, different way of thinking - and this is not going to work (just as a dispassionate analysis of the benefits to the family as a whole will not persuade the hard-working brewer to give half his fortune to his idle relations). At least it is not going to produce the result that innocent bioethicists hope it will.

However, not all bioethicists are innocent. As I have shown, conventional bioethics problem-solving cannot produce convincing solutions in a context that operates according to different rules. But, so long as bioethicists accept that context and work within it they can act to legitimise it - either simply by endorsing it and making it look ethical, or by becoming part of the fabric of the context and so strengthening that fabric against other alternative fabrics.

Innocent bioethicists do not realise this, but those other bioethicists who do, actively support the system. And those who do support the system might as well come out and say so openly. Not to do so is not only significantly to mislead many of the public who tend to assume that medicine must be becoming more ethical because there is so much more discussion of medical ethics - but it is to play a certain type of game in a playground where other games with other rules are also played. In this playground the children playing the other games may well be mildly amused by this behaviour, and will certainly be pleased if the games of the bioethicists distract attention from the much more serious and much more powerful games they are engaged in.
To conclude, I believe there are two potentially productive paths open to bioethics, neither of which are being pursued by most bioethicists at the moment. The first is to stand outside the system and not take any of it for granted - to do political philosophy in the traditional sense. The second is to take health systems for what they really are - that is, to see them as tribal systems, to grasp their nature as it appears to those within that culture, and then - if this is felt desirable - to change the system by using the ways of that culture. In other words to seek change as you would in a family, or a tribe - and so to work in a partly logical, partly emotional fashion to work in a way that acknowledges history and culture (and so to be logically corrupt in a way accepted by that tribe). The alternative for bioethics is stagnation and, ultimately, extinction.

I prefer the first path - to try to examine the system from the outside - and I believe it is only by taking this path that we can begin to talk constructively about health care rationing.

This is a revised version of a paper given at the International Seminar on Bioethics at Knox College, University of Otago, Dunedin, New Zealand in November, 1993.

David Seedhouse, $B A, P h D$, is Senior Lecturer in Medical Ethics, the Department of Psychiatry and Behavioural Science and Editor of Health Care Analysis: Journal of Health Philosophy and Policy.

\section{References}

(1) Maynard A, Hutton J. Health care reform: the search for the holy grail. Health economics 1992; 1: 1-3.

(2) Harris J. Unprincipled QALYs: a response to Cubbon. Fournal of medical ethics 1991; 17: 185-188.

(3) Williams A. Cost effectiveness analysis: is it ethical? fournal of medical ethics 1992; 18: 7-11.

(4) Williams A. Ethics and efficiency in the provision of health care. In: Bell J M, Mendus S, eds. Philosophy and medical welfare. Cambridge: Cambridge University Press, 1988: 112.

(5) Callahan D. Setting limits: medical goals in an ageing society. New York: Touchstone, 1987.

(6) Black D. Paying for Health. Fournal of medical ethics 1991; 17: 117-123.

(7) Langford J $M$. Who should get the kidney machine? fournal of medical ethics 1992; 18: 12-17.

(8) Seedhouse D F. Rationality. PhD thesis [unpublished], 1984.

(9) Beauchamp T L, Childress J F. Principles of Biomedical Ethics [4th ed] (especially ch 1). New York: Oxford University Press, 1994.

(10) Seedhouse D F. Fortress NHS: a philosophical review of the National Health Service. Chichester: John Wiley and Sons, 1994. 